\title{
Two new twisted helical nickel(II) and cobalt(III) octahedral monomer complexes: Synthesis and structural characterization
}

\author{
MALAY DOLAI and MAHAMMAD ALI* \\ Department of Chemistry, Jadavpur University, Kolkata 700 032, India \\ e-mail: mali@chemistry.jdvu.ac.in
}

MS received 16 November 2013; revised 21 April 2014; accepted 27 April 2014

\begin{abstract}
Two mononuclear complexes namely $\left[\mathrm{Ni}^{\mathrm{II}}(\mathrm{L})\right](\mathbf{1})$ and $\left[\mathrm{Co}{ }^{\mathrm{III}}(\mathrm{L})\right]\left(\mathrm{NO}_{3}\right)(2)$ of a hexacoordinating $\mathrm{N}_{4} \mathrm{O}_{2}$ donor Schiff base ligand were synthesized and characterized by single crystal X-ray studies. In compound 2 the central cobalt is in +3 oxidation state while 'in' compound $\mathbf{2}$, the nickel ion is in +2 oxidation state. The two complexes are isostructural with octahedral coordination environment exhibiting helical twist topology. They also display strong H-bonding as well as $\mathrm{CH}-\pi$ interactions to generate $1 \mathrm{D}$ chain.
\end{abstract}

Keywords. Coordination chemistry; nickel(II); cobalt(III); Schiff base; twisted helicity; supramolecular interactions.

\section{Introduction}

Over the last few years, there has been an immense research interest among the chemists towards the investigations of biological properties of nickel that lead to several structural and biochemical models. ${ }^{1,2}$ Variable oxidation states coupled with multitude of coordination geometries are the most interesting aspects that have been identified in the active site of many Ni-containing enzymes. ${ }^{3}$ Several biomimetic $\mathrm{Ni}^{\mathrm{II}}$ complexes have been found to act as structural and functional models of metalloenzymes, ${ }^{4}$ such as the Ni-Fe hydrogenase ${ }^{5-7}$ or the CO dehydrogenase/acetyl coenzyme-A synthase, ${ }^{8,9}$ etc.

The importance of helicates is related to the development and the understanding of self-assembly in supramolecular chemistry ${ }^{10}$ that are frequently perceived in biology and in physics. ${ }^{11,12}$ Intense research activities have been focused on this new field in order to explore and apply its power of design and control for the selective preparation of complicated organized chemical architectures. The fundamental research on helicates has recently led to a new fascinating metallosupramolecular architectures based on multicomponents self-assemblies such as directional light-converting devices, ${ }^{13}$ inorganic two-dimensional racks, ladders ${ }^{14}$ and grids, ${ }^{15}$ intertwined catenanes and knots, ${ }^{16}$ and allosteric ionophores. ${ }^{17}$ On the other hand, $\mathrm{CH}-\pi,{ }^{18} \pi-\pi,{ }^{19}$ cation $-\pi,{ }^{20}$, anion- $\pi,{ }^{21}$ etc. interactions have been found to play crucial roles in molecular

\footnotetext{
*For correspondence
}

recognition, molecular assembly, and crystal packing of organic materials, nanomaterials and biomolecules. ${ }^{22}$ In this context, the occurrence of $\mathrm{CH} \cdots \pi$ interactions in solid-state networks has been extensively described, ${ }^{18,19}$ and their importance as stabilizing weak forces have been clearly illustrated in molecular structures. ${ }^{19-22}$

Hence, in this work, an octahedral complex, with $\mathrm{NiO}_{2} \mathrm{~N}_{4}$ chromophore has been investigated (figure 1) along with an isostructural $\mathrm{Co}^{\mathrm{III}}$ complex of the same ligand (scheme 1).

Both $\left[\mathrm{Ni}^{\mathrm{II}} \mathrm{L}\right] \cdot \mathrm{H}_{2} \mathrm{O}$ (1) and $\left[\mathrm{Co}^{\mathrm{III}} \mathrm{L}\right] \cdot \mathrm{NO}_{3}$ (2) complexes were prepared by reacting equimolar quantities of $\mathrm{M}^{\mathrm{II}}$ and $\left(\mathrm{H}_{2} \mathrm{~L}\right)$ (scheme 1$)$ in acetonitrile in presence of two equivalents of tryethylamine(TEA) as a base. Here, we are going to discuss the syntheses and structural characterization of two new $\mathrm{Ni}^{\mathrm{II}}$ and $\mathrm{Co}^{\mathrm{III}}$ octahedral complexes that exhibit twisted helicity and $\mathrm{H}-$ bonding as well as $\mathrm{CH}-\pi$ interactions to generate $1 \mathrm{D}$ chain.

\section{Experimental}

\subsection{Materials}

Chemicals such as 3-methoxy-salicylaldehyde (vanillin), $\mathrm{N}, \mathrm{N}^{\prime}$-bis(3-aminopropyle)-ethylene-diamine(Aldrich), $\mathrm{Co}\left(\mathrm{NO}_{3}\right)_{2}, \mathrm{Ni}\left(\mathrm{NO}_{3}\right)_{2}$ and triethylamine (TEA) (Merck, India) are of reagent grade and used without further purification. Solvents like methanol, ethanol, acetonitrile (Merck, India) were of reagent grade and used as received. 


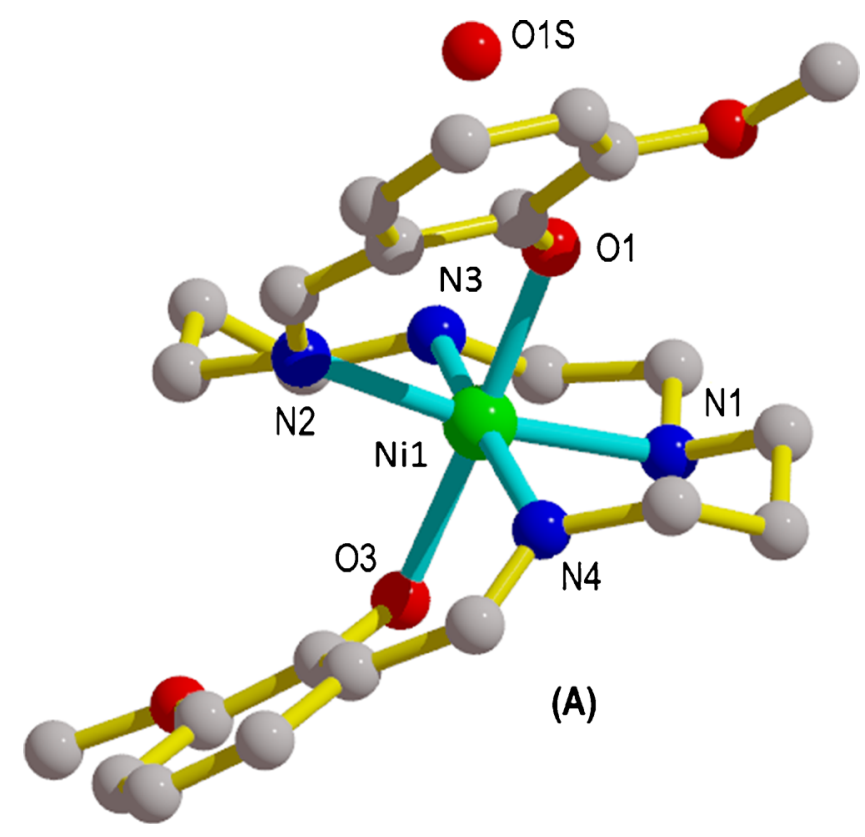

Figure 1. (a) Molecular view of complex 1. All H-atoms are omitted for clarity. Symmetry code: a) $x, y, z ; b)-x,-$ $\mathrm{y}, 1 / 2+\mathrm{z}$; c) $1 / 2-\mathrm{x}, 1 / 2+\mathrm{y}, 1 / 2+\mathrm{z}$; d) $1 / 2+\mathrm{x}, 1 / 2-\mathrm{y}, \mathrm{z}$.

2.1a Synthesis of ligand $\left(H_{2} L\right)$ : The Schiff base ligand was obtained by condensation of N,N'-bis(3amino-propyle)ethylenediamine (1.74 g, $10 \mathrm{mmol}$.) and $o$-vanillin $(3.04 \mathrm{~g}, 20 \mathrm{mmol}$.) in ethanol by stirring at $60^{\circ} \mathrm{C}$ for 4 hours, during which time a yellow solid separated out from the reaction mixture. The analytically pure solid was dried, and stored in vacuum over anhydrous $\mathrm{CaCl}_{2}$ for subsequent use. Yield: $3.31 \mathrm{~g}$ (75\%). Anal. Calcd. for $\mathrm{C}_{24} \mathrm{H}_{34} \mathrm{O}_{4} \mathrm{~N}_{4}(\mathrm{MW}=442.55): \mathrm{C} 65.13 \%, \mathrm{H} 7.74 \%$, $\mathrm{N} 12.65 \%$. Found: $\mathrm{C} 64.96 \%, \mathrm{H} 7.75 \%$, and $\mathrm{N}$ $12.42 \% .{ }^{1} \mathrm{H}$ NMR (300 $\mathrm{MHz}, \mathrm{CDCl}_{3}$ ) (figure $\mathrm{S} 1$ ): $\delta 1.24(\mathrm{~s}, 2 \mathrm{H}$, imine*, not detectable precisely), 1.64-1.84 (m, 4H, methylene), 2.30-2.40 (d, 4H, methylene), 2.53-2.74 (d, 4H, methylene), 3.50-3.44 (d, 4H, methylene), 3.90 (s, 6H, methoxy), 6.88-7.28 (d, 2H, H4), (m, 6H, aromatic), 8.28 (s, 2H, azomethine), 13.3125 (s, 2H, phenoxo-OH).

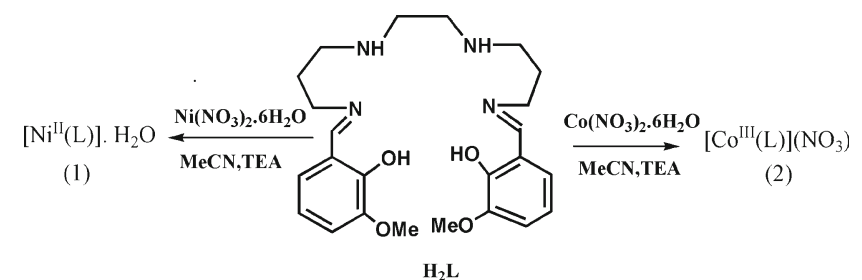

Scheme 1. Schematic representation of formation of complexes. 2.1b Synthesis of $[\mathrm{Ni}(\mathrm{L})]\left(\mathrm{H}_{2} \mathrm{O}\right)(1)$ : It was prepared by adding ligand $\left(\mathrm{H}_{2} \mathrm{~L}\right)(0.442 \mathrm{~g}, 1.0 \mathrm{mmol}$. $)$ to a stirring acetonitrile solution $(30 \mathrm{~mL})$ of $\mathrm{Ni}\left(\mathrm{NO}_{3}\right)_{2} \cdot 6 \mathrm{H}_{2} \mathrm{O}$ $(0.291 \mathrm{~g}, 1.0 \mathrm{mmol})$ to give a pale yellow solution, after a while a solution of TEA $(0.202 \mathrm{~g}, 2.0 \mathrm{mmol})$ was added for the deprotonation of ligand which resulted in a brown solution. It was stirred for additional $20 \mathrm{~m}$ and filtered and then kept aside undisturbed for slow evaporation. After 3 days, the orange rectangular block-shaped crystals suitable for X-ray diffraction were formed. Yield: $2.83 \mathrm{~g}(55 \%)$. Anal. Calcd. for $\mathrm{C}_{24} \mathrm{H}_{34} \mathrm{~N}_{4} \mathrm{NiO}_{5}$ : C 55.72\%, H 6.63\%, N 10.83\%. Found: $\mathrm{C} 55.96 \%$, H $7.05 \%$, and N $10.42 \%$.

2.1c Synthesis of $[\mathrm{Co}(\mathrm{L})]\left(\mathrm{NO}_{3}\right)(2)$ : It was prepared in the same way as for $[\mathrm{Ni}(\mathrm{L})]\left(\mathrm{H}_{2} \mathrm{O}\right)$ with the exception that $\mathrm{Co}\left(\mathrm{NO}_{3}\right)_{2} \cdot 6 \mathrm{H}_{2} \mathrm{O}(0.293 \mathrm{~g}, 1.0 \mathrm{mmol})$ was taken instead of $\mathrm{Ni}\left(\mathrm{NO}_{3}\right)_{2} \cdot 6 \mathrm{H}_{2} \mathrm{O}$. In 3 days, the dark brown block-shaped crystals suitable for X-ray diffraction were formed. Yield: $4.37 \mathrm{~g}(78 \%)$. Anal. Calcd. for $\mathrm{C}_{24} \mathrm{H}_{32} \mathrm{CoN}_{5} \mathrm{O}_{7}$ : C 51.33\%, H 5.74\%, N $12.47 \%$. Found: C $50.96 \%$, H 5.75\%, and N $12.49 \%$.

\subsection{Physical measurements}

Elemental analyses were carried out using a PerkinElmer 240 elemental analyzer. ${ }^{1} \mathrm{H}$ NMR spectrum was recorded on a Bruker $300 \mathrm{MHz}$ NMR spectrometer using trimethylsilane as an internal standard in $\mathrm{CDCl}_{3}$. Electronic spectra were recorded from Agilent 8453 UV-vis diode-array spectrophotometer.

\subsection{Crystallography}

Single crystal X-ray data of complexes $\mathbf{1}$ and $\mathbf{2}$ were collected on a Bruker SMART APEX-II CCD diffractometer using graphite monochromated Mo-K $\mathrm{K}_{\alpha}$ radiation $(\lambda=0.71073 \AA)$. Data collection, reduction, structure solution, and refinement were performed using the Bruker APEX-II suite (v2.0-2) program. All available reflections to $2 \theta_{\max }$ were harvested and corrected for Lorentz and polarization factors with Bruker SAINT plus. Reflections were then corrected for absorption, inter frame scaling, and other systematic errors with SADABS. ${ }^{23}$ The structures were solved by the direct methods and refined by means of full matrix least-square technique based on $F^{2}$ with SHELX-97 software package. ${ }^{24}$ All the non-hydrogen atoms were refined with anisotropic thermal parameters. All the hydrogen atoms belonging to carbon and nitrogen atoms were placed in their geometrically idealized positions, while hydrogen atoms on oxygen atoms 
of non-coordinated water was found on the difference Furior map, and all of them were constrained to ride on their parent atoms. Drawings of molecules were generated with the program DIAMOND-3.0 and PLATON1.16. The crystallographic data for $\mathbf{1}$ and $\mathbf{2}$ are given in table 1.

\section{Results and Discussion}

Synthesis $\left[\mathrm{Ni}^{\mathrm{II}}(\mathrm{L})\right] \cdot \mathrm{H}_{2} \mathrm{O}$ and $\left[\mathrm{Co}{ }^{\mathrm{III}}(\mathrm{L})\right]\left(\mathrm{NO}_{3}\right)$ complexes were prepared by reacting the respective $\left(\mathrm{Ni}^{\mathrm{II}}\right.$ and $\left.\mathrm{Co}^{\mathrm{II}}\right)$ metal ions with 1 equivalent of hexacoordinating ligand $\mathrm{H}_{2} \mathrm{~L}$ in presence of 2 equivalents of TEA in acetonitrile. It was interesting to note that $\mathrm{Co}^{\mathrm{II}}$ ion is oxidized to $\mathrm{Co}^{\mathrm{III}}$ in presence of hard-donor $\left(\mathrm{N}_{4} \mathrm{O}_{2}\right)$ atoms probably by the atmospheric oxygen as evidenced from the charge balance of the formed complex and also by BVS calcualtions (vide infra).

\subsection{Structural description}

The structure of $[\mathbf{N i}(\mathbf{L})]\left(\mathbf{H}_{2} \mathbf{O}\right)(\mathbf{1})$ is shown in figure 1 . The complex $\mathbf{1}$ crystallizes in a orthorhombic space group Pna21. The coordination sphere of the hexacoordinated $\mathrm{Ni}^{\mathrm{II}}$ metal centre is surrounded by $\mathrm{N}_{4} \mathrm{O}_{2}$ atoms of the Schiff base ligand $\left(\mathrm{H}_{2} \mathrm{~L}\right)$. The four $\mathrm{N}$ atoms (namely $\mathrm{N} 1, \mathrm{~N} 2, \mathrm{~N} 3$ and $\mathrm{N} 4$ ) from the $\mathrm{N}, \mathrm{N}^{\prime}-$ bis(3-amino-propyle)ethylenediamine part of the ligand are coordinated to nickel(II) centre and the two $\mathrm{O}$ atoms (O1 and $\mathrm{O} 3$ ) from the phenolic $-\mathrm{OH}$ groups of the two $o$-vanillin moieties of ligand, coordinate axially to the metal centre thereby forming a complete octahedral geometry. The Ni-N bond distances are in the range $2.020-2.096 \AA$ and Ni-O bond distances 2.038$2.040 \AA$. All the bond distances are found to be almost identical. Bond distances and bond angles are listed in table $2 \mathrm{a}$.

The structure of $[\mathrm{Co}(\mathrm{L})]\left(\mathrm{NO}_{3}\right)$ (2) is shown in figure 2. The complex 2 crystallizes in a orthorhombic space group Pccn. The coordination environment arround the $\mathrm{Co}^{\mathrm{III}}$ metal centre is same as that of complex 1. The four $\mathrm{N}$ atoms $(\mathrm{N} 1$ and $\mathrm{N} 2$ and their symmetry related counter parts) from the $\mathrm{N}, \mathrm{N}^{\prime}$-bis(3aminopropyle)ethylenediamine part of the ligand coordinate to Col to form the square plane and two $\mathrm{O}$ atoms (O2 and its symmetry related counter part) from the phenolic $-\mathrm{OH}$ groups of two $o$-vanillin moieties, occupy the axial positions giving an octahedral geometry. The Co- $\mathrm{N}$ bond distances are in the range 1.933$1.976 \AA$ while Co-O bond distances are almost equal $(\sim 1.890 \AA)$. The shorter axial Co-O bond length than the equatorial Co-N bond length is in conformity with the results observed previously in cobalt(III) complexes of comparable ligand environment ${ }^{25}$ (table $2 \mathrm{~b}$ ).

Table 1. Crystallographic data and details of the structure determination for 1-2.

\begin{tabular}{|c|c|c|}
\hline & 1 & 2 \\
\hline & (CCDC No.-894740) & (CCDC No.-894739) \\
\hline Formula & $\mathrm{C}_{24} \mathrm{H}_{32} \mathrm{~N}_{4} \mathrm{Ni} \mathrm{O}_{4}, \mathrm{H}_{2} \mathrm{O}$ & $\mathrm{C}_{24} \mathrm{H}_{32} \mathrm{Co} \mathrm{N}_{4} \mathrm{O}_{4}, \mathrm{~N} \mathrm{O}_{3}$ \\
\hline FW & 517.24 & 561.48 \\
\hline Crystal System & Orthorhombic & Orthorhombic \\
\hline Space group & Pna21 (No. 33) & Pccn (No. 56) \\
\hline a/ $\AA$ & $37.5238(12)$ & $7.4561(3)$ \\
\hline$b / \AA$ & $7.5017(2)$ & $18.4285(6)$ \\
\hline$c / \AA$ & $8.6868(3)$ & $19.1192(7)$ \\
\hline$\alpha /^{\circ}, \beta /^{\circ}, \gamma /^{\circ}$ & 90 & 90 \\
\hline$V / \AA^{3}$ & $2445.27(13)$ & $2627.07(17)$ \\
\hline$Z$ & 4 & 4 \\
\hline$\left.\rho_{\text {calc }} / \mathrm{g} \mathrm{cm}^{-3}\right]$ & 1.405 & 1.420 \\
\hline$\mu\left(\mathrm{Mo}-\mathrm{K}_{\alpha}\right) / \mathrm{mm}^{-1}$ & 0.836 & 0.705 \\
\hline$F(000)$ & 1096 & 1176 \\
\hline Theta Min-Max $\left[^{\circ}\right]$ & $1.1,32.6$ & $2.1,27.1$ \\
\hline Index ranges & $-56: 56 ;-11: 11 ;-13: 13$ & $-9: 9 ;-23: 23 ;-24: 24$ \\
\hline Reflection collected & 35271 & 20284 \\
\hline Independent reflections $\left(\mathrm{R}_{\text {int }}\right)$ & $7937(0.038)$ & $2908(0.026)$ \\
\hline No. Of Parameter & 361 & 174 \\
\hline GOF & 1.11 & 1.026 \\
\hline $\mathrm{R}_{1}[I>2 \sigma(I)]$ & $0.0509((6648)$ & $0.0355(2261)$ \\
\hline $\mathrm{wR}_{2}$ (all data) & 0.1012 & 0.0979 \\
\hline Min. and Max. Resd. Dens./e $\AA^{-3}$ & $-0.93,0.38$ & $-0.27,0.30$ \\
\hline
\end{tabular}


Table 2. Summary of bond distances and bond angles of complexes $\mathbf{1}$ and $\mathbf{2}$.

(i) Complex 1.

Bond lengthes $(\AA)$

Ni1- N1

Ni1- N4

$2.020(10)$

Ni1- O3

$2.057(3)$

$2.073(2)$

Ni1- O1

$2.0819(17)$

Ni1- N3

$2.116(3)$

Ni1- N2

$2.066(2)$

Bond angles $\left({ }^{\circ}\right)$

N1- Ni1- N2

169.91(10)

N4- Ni1- N2

$88.56(9)$

O3- Ni1- N2

$92.83(8)$

O1 - Ni1- N2

84.53(8)

Bond angles $\left(^{\circ}\right)$

N1- Ni1- N4

88.56(9)

N1- Ni1- O3

93.19(8)

N4- Ni1- O3

84.15(8)

N1- Ni1- O1

90.04(8)

N4- Ni1-O1

92.17(8)

O3- Ni1-O1

175.04(7)

N1- Ni1- N3

83.57(10)

N4- Ni1- N3

169.05(10)

O3- Ni1- N3

88.69(9)

O1- Ni1- N3

95.42(9)

N3- Ni1-N2

88.47(10)

(ii) Complex 2.

Bond lengthes $(\AA)$

Co1- O2

1.8901(12)

Co1- O2a

1.8901(12)

O2a- Co1- N1a

$89.55(5)$

N1- Co1- N1a

93.61(6)

1.9332(15)

O2- Co1- N2

85.90(6)

Co1- N1a

$1.9332(15)$

O2- Co1- N2a

89.95(6)

Co1- N2

$1.9742(15)$

N1- Co1- N2a

$90.12(6)$

$1.9742(15)$

N1- Co1- N2

$174.32(6)$

Bond angles $\left({ }^{\circ}\right)$

O2a- Co1- N2

$89.95(6)$

$174.30(5)$

O2a- Co1- N2a

$85.90(6)$

$89.55(5)$

N1- Co1- N2a

90.12(6)

94.36(5)

N1a- Co1- N2a

$174.32(6)$

O2- Co1- N1a

94.36(5)

N2- Co1- N2a

$86.49(6)$

Symmetry code: $\mathrm{a}=1 / 2-\mathrm{x}, 1 / 2-\mathrm{y}, \mathrm{z}$.

Space-filling representation of $[\mathrm{Ni}(\mathbf{L})]$ and $[\mathrm{Co}(\mathbf{L})]^{+}$ clearly demonstrates mononuclear single-stranded helical structures for both the complexes figures S2 and S3. It is generally accepted that a central metal ion

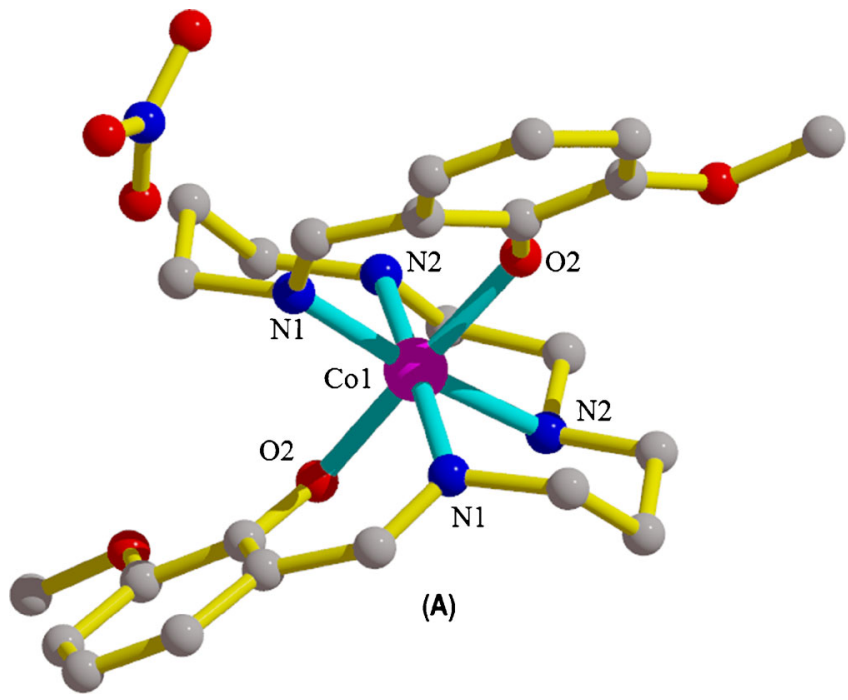

Figure 2. (a) Molecular view of complex 2. All H-atoms are omitted for clarity. Symmetry code: a) $\mathrm{x}, \mathrm{y}, \mathrm{z}$; b) $1 / 2+\mathrm{x}$, $-y, 1 / 2-z$; c) $-x, 1 / 2+y, 1 / 2-z$; d) $1 / 2-x, 1 / 2-y, z$; e) $-x,-y,-z$; f) $1 / 2-\mathrm{x}, \mathrm{y}, 1 / 2+\mathrm{z} ; \mathrm{g}) \mathrm{x}, 1 / 2-\mathrm{y}, 1 / 2+\mathrm{z}$; h) $1 / 2+\mathrm{x}, 1 / 2+\mathrm{y},-\mathrm{z}$. which is too small to fit into the cavity of the bound multidentate ligand may generate such topology. Steric interactions between the extremities of the strand induce a slight twisting of the ligand, reminiscent of that found in organic helicenes. ${ }^{26}$ Several acyclic polyglycols and linear podands wrap around group I and II metals ${ }^{27}$ as exemplified by the carbocyclic antibiotic monensin which gives the mononuclear single-stranded helical complex. ${ }^{28}$ Here the helical twist is favoured by the attachment of rigid and bulky terminal aromatic groups (o-vanillin) to comparatively flexible central $\mathrm{N}, \mathrm{N}^{\prime}$-bis(3-aminopropyle)ethylenediamine moiety. The angles between the two planes constructed from two $O$ vanillin moieties is found to be $30.92^{\circ}$ and $36.06^{\circ}$ for complexes $\mathbf{1}$ and $\mathbf{2}$, respectively which clearly demonstrate the fact of helical twisting observed in $\mathbf{1}$ and $\mathbf{2}$.

In case of complex $\mathbf{1}$ there is one non-coordinated water molecule (O1S) that is involved in four-ways H-bonding interactions namely, N1-H1... O1S, N3$\mathrm{H} 45 \cdots \mathrm{O} 1 \mathrm{~S}$, O1S-H55 .. O1 and O1S-H40 ... O3. It forms two H-bonds with two amine nitrogen atoms $\mathrm{N} 1, \mathrm{~N} 3$ and with two phenolate oxygen atoms (O1 and O3) belonging to two neighbouring complexes on either sides (figure 3a). Spiral binding of complex 1 through $\mathrm{H}$-bonding is shown in figure $3 \mathrm{~b}$. In cobalt(III) complex 

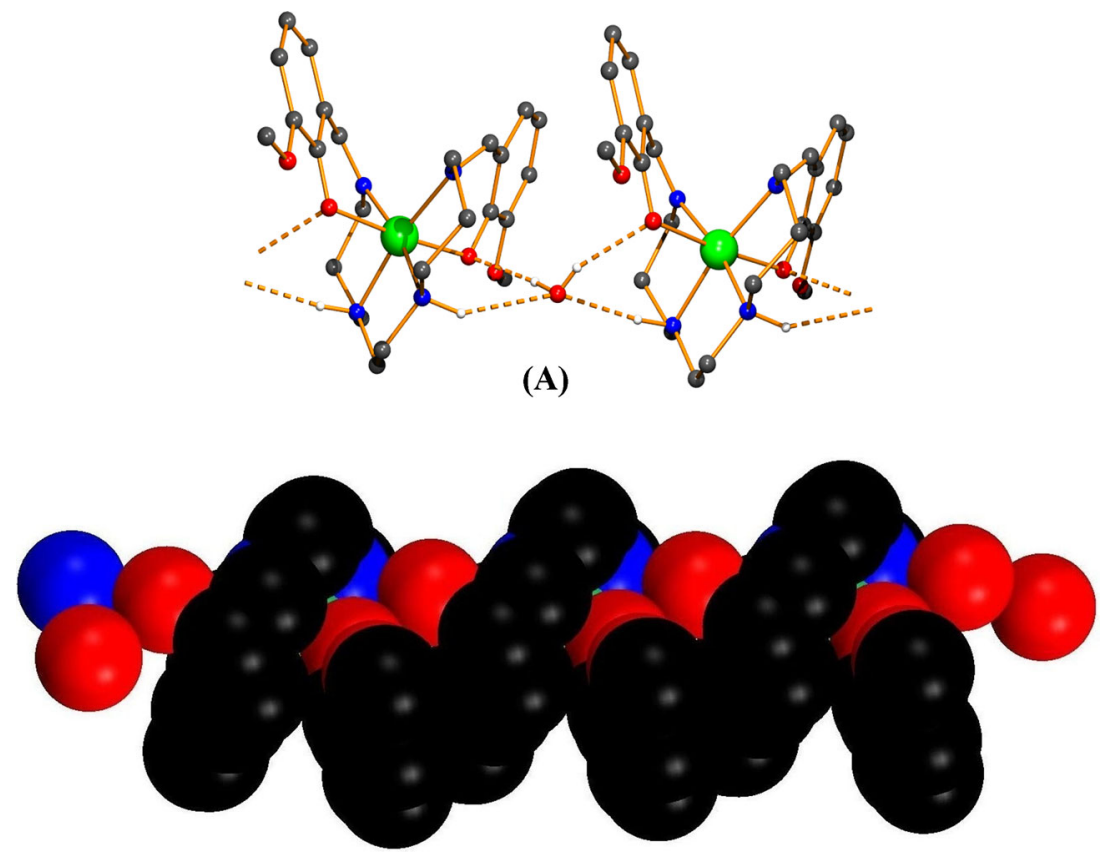

(B)

Figure 3. (a)The quasi 1D chain through bifurcated H-bonding interaction in complex 1. (b) Space-filling model showing Spiral binding of complex 1 through H-bonding. N1-H1 . . O1S: H1 . . O $1 \mathrm{~S}=2.11(4) \AA, \mathrm{N} 1-\mathrm{H} 1=0.92(4)$ $\AA, \mathrm{N} 1 \cdots \mathrm{O} 1 \mathrm{~S}=3.022(4) \AA,<\mathrm{N} 1-\mathrm{H} 1 \cdots \mathrm{O} 1 \mathrm{~S}=173(3)^{\circ}$; O1S-H40 $\cdots \mathrm{O} 3$ : $\mathrm{H} 40 \cdots \mathrm{O} 3=2.11(3) \AA$, O1S-H40 $=0.78(3) \AA$, O1S $\cdots \mathrm{O} 3=2.848(4)$ $\AA,<\mathrm{O} 1 \mathrm{~S}-\mathrm{H} 40 \cdots \mathrm{O} 3=160(3)^{\circ}$; N3-H45 $\cdots \mathrm{O} 1 \mathrm{~S}: \mathrm{H} 45 \cdots \mathrm{O} 1 \mathrm{~S}=2.45(4) \AA$, $\mathrm{N} 3-\mathrm{H} 45=0.98(4) \AA, \mathrm{N} 3 \cdot . \mathrm{O} 1 \mathrm{~S}=3.323(4) \AA,<\mathrm{N} 3-\mathrm{H} 45 \cdots \mathrm{O} 1 \mathrm{~S}=$ $148(3)^{\circ}$; O1S-H55 ... O1: H55 . . O $1=1.97(4) \AA$, O1S-H55 = 0.87(4) $\AA$, $\mathrm{O} 1 \mathrm{~S} \cdot \cdots \mathrm{O} 1=2.817(3) \AA,<\mathrm{O} 1 \mathrm{~S}-\mathrm{H} 55 \cdots \mathrm{O} 1=2.817(3)^{\circ}$.

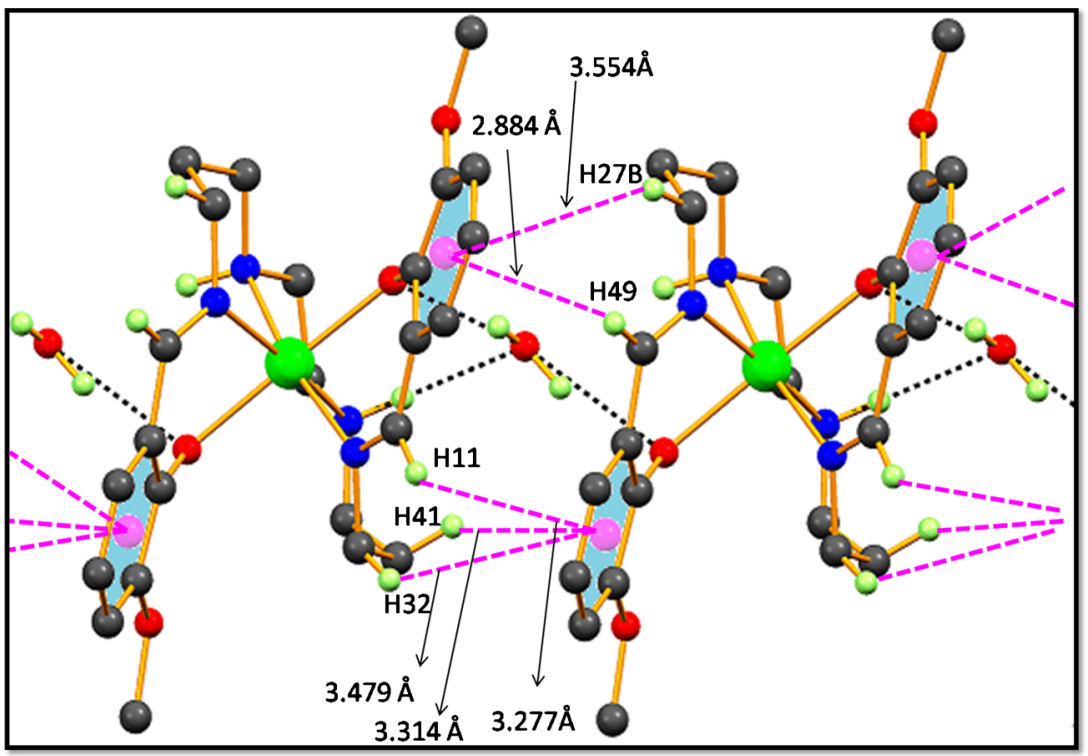

Figure 4. The one dimensional $\mathrm{CH} \cdot \cdots$ pi(phenyl) interactions (dotted lines in magenta colors) and supramolecular H-bonding(dotted lines in black colors) are observed in complex $\mathbf{1}$. 
Table 3. C-H... Interaction for Complexes 1 and 2.

\begin{tabular}{|c|c|c|c|c|}
\hline interaction & atoms & distances $\mathrm{H} \cdots \mathrm{Cg}(\AA)$ & $\angle \mathrm{C}-\mathrm{H} \cdot \cdots \mathrm{Cg}\left({ }^{\circ}\right)$ & distances $\mathrm{C}(\mathrm{H}) \cdots \mathrm{Cg}(\AA)$ \\
\hline \multicolumn{5}{|c|}{ Complex 1} \\
\hline C-H $\cdots \pi$ (phenyl) & $\mathrm{C}(26)-\mathrm{H}(49) \cdots \mathrm{Cg}(1)$ & 2.884 & 132.55 & 3.582 \\
\hline $\mathrm{C}-\mathrm{H} \cdots \pi$ (phenyl) & $\mathrm{C}(27)-\mathrm{H}(27 \mathrm{~B}) \cdots \mathrm{Cg}(1)$ & 3.554 & 134.83 & 4.294 \\
\hline $\mathrm{C}-\mathrm{H} \cdots \pi$ (phenyl) & $\mathrm{C}(11)-\mathrm{H}(11) \cdots \mathrm{Cg}(2)$ & 3.277 & 108.44 & 3.679 \\
\hline $\mathrm{C}-\mathrm{H} \cdot \cdots \pi$ (phenyl) & $\mathrm{C}(29)-\mathrm{H}(32) \cdots \mathrm{Cg}(2)$ & 3.479 & 118.01 & 3.999 \\
\hline $\mathrm{C}-\mathrm{H} \cdots \pi$ (phenyl) & $\mathrm{C}(30)-\mathrm{H}(41) \cdots \mathrm{Cg}(2)$ & 3.314 & 131.19 & 4.040 \\
\hline \multicolumn{5}{|c|}{ Complex 2} \\
\hline $\mathrm{C}-\mathrm{H} \cdot \cdots \pi$ (phenyl) & $\mathrm{C}(10)-\mathrm{H}(10 \mathrm{~B}) \cdots \mathrm{Cg}(3)$ & 3.441 & 100.65 & 3.744 \\
\hline $\mathrm{C}-\mathrm{H} \cdot \cdots \pi$ (phenyl) & $\mathrm{C}(9)-\mathrm{H}(9 \mathrm{~A}) \cdots \mathrm{Cg}(3)$ & 3.265 & 129.49 & 3.953 \\
\hline
\end{tabular}

$\mathrm{Cg}(1)=\mathrm{C} 15 \mathrm{C} 14 \mathrm{C} 100 \mathrm{C} 13 \mathrm{C} 12 \mathrm{C} 17$ and $\mathrm{Cg}(2)=\mathrm{C} 18 \mathrm{C} 19 \mathrm{C} 20 \mathrm{C} 21 \mathrm{C} 1 \mathrm{C} 2$ denotes for complex 1, Cg (3) = C3 C13 C4 C5 C6 C7 denotes for complex 2.

2, there is strong $\mathrm{H}$-bonding interaction between $\mathrm{H}$ atom on $\mathrm{N} 2$ (imine nitrogen) and $\mathrm{O} 3$ (non-coordinated $\mathrm{NO}_{3}^{-}$) atom and extended in $1 \mathrm{D}$ fashion. Details of H-bonding interactions are shown in figure 3 for $\mathbf{1}$ figure S4 for 2.

On the other hand, the packing of the molecules in both complexes $\mathbf{1}$ and $\mathbf{2}$ is controlled by $\mathrm{CH} \cdots \pi$ as well as by $\mathrm{H}$-bonding interactions between two neighboring complex units to give compact 1D supramolecular architectures. In complex 1, five types of $\mathrm{CH} \cdots \pi$ (phenyl) interactions are prevalent (figure 4). Among them, three $\mathrm{CH} \cdots \pi$ interactions are established between two methylenic and one azomethine H-atoms of one complex with the centroid of the phenyl ring of its neighboring complex. Similarly, two $\mathrm{CH} \cdots \pi$ ineractions are established between one methylenic and one azomethine $\mathrm{H}$ atoms and the centroid of the phenyl ring of other complex. These two centroids belong to two different neighboring complexes. These $\mathrm{CH} \cdot \cdots \pi$ interactions fall in the range $2.884-3.554 \AA$. Details of $\mathrm{CH} \cdot \cdots \pi$ interactions are given in table 3 . In complex 2, only two types of $\mathrm{CH}$-pi interactions are present (figure S5), they are established between methylenic $\mathrm{H}$ atoms (H10B and H9A) and neighboring phenyl ring of Schiff base with distances $3.441 \AA$ and $3.265 \AA$.

\section{$3.2 U V$-vis spectra of complexes 1 and 2}

The electronic spectra of complexes $\mathbf{1}$ and $\mathbf{2}$ were recorded in $\mathrm{MeCN}$ (figure 5). The electronic transition appears at $\sim 373 \mathrm{~nm}$ with molar extinction coefficients $(\varepsilon) 3280 \mathrm{dm}^{3} \mathrm{~mol}^{-1} \mathrm{~cm}^{-1}$ for complex $\mathbf{1}$. In case of complex 2 there are two electronic transitions that appear at 633 and $402 \mathrm{~nm}$ with $\varepsilon$ values 392 and $7540 \mathrm{dm}^{3} \mathrm{~mol}^{-1} \mathrm{~cm}^{-1}$, respectively. The bands at longer wavelengths may be attributed to the d-d transitions for complex $2(633 \mathrm{~nm})$ but no d-d transition is observed in complex $\mathbf{1}$. The bands at shorter wavelengths (373 and $402 \mathrm{~nm}$ ) are due to ligand to metal $(\mathrm{L} \rightarrow \mathrm{M})$ charge-transfer transitions.

\subsection{BVS calculation}

Bond valence sum (BVS) method is very frequently used to examine the nature of coordination and oxidation state of the central metal atom using the crystallographic data in coordination complexes as well as in many biological molecules. The most successfully used empirical equation is:

$$
\sum s_{\mathrm{ij}}=\sum \exp \left(r_{\circ}-r_{\mathrm{ij}}\right) / 0.37
$$

Where $r_{\circ}$ is a parameter characteristic of the bond and $r_{\mathrm{ij}}$ is the crystallographically obtained bond distances.

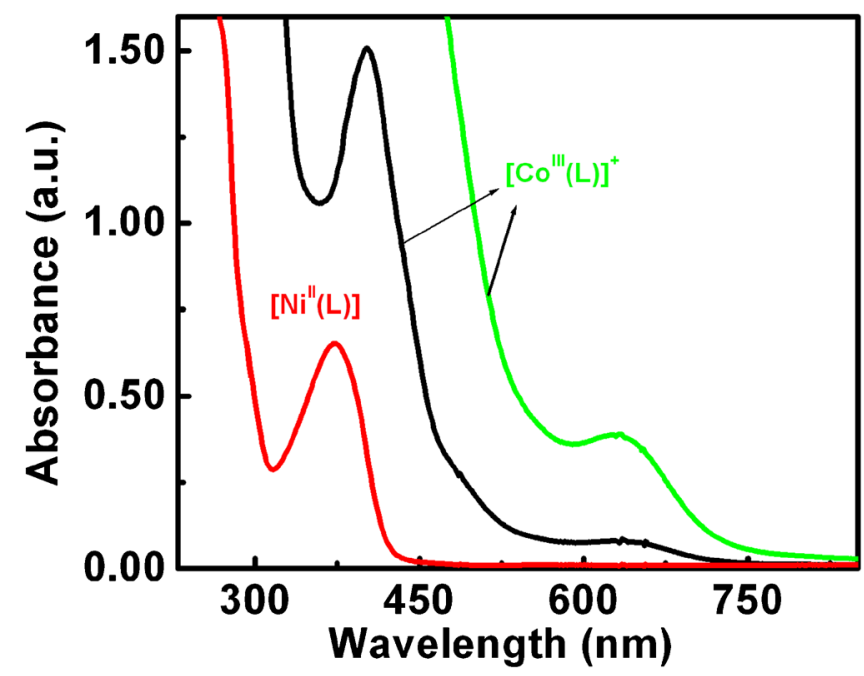

Figure 5. UV-vis spectra of complexes $\mathbf{1}$ and $\mathbf{2}$ in $\mathrm{MeCN}$. $[\mathrm{c}]=1.0 \times 10^{-3} \mathrm{M}$ for $\mathrm{d}-\mathrm{d}$ bands at longer wavelengths $\left(633 \mathrm{~nm}\right.$, green line) for complex 2 and $[\mathrm{c}]=1.0 \times 10^{-5} \mathrm{M}$ for LMCT bands at shorter wavelengths $(373 \mathrm{~nm}$, red line for $\mathbf{1}$ and $402 \mathrm{~nm}$, black line for 2). 
$\Sigma s_{\mathrm{ij}}$ represents the charge on the central metal atom. BVS values ${ }^{13}$ are: $\mathrm{Ni}^{\mathrm{II}}-\mathrm{O}=1.670 \AA$. $\mathrm{Ni}^{\mathrm{II}}-\mathrm{N}=1.647 \AA$. The BVS of Ni was calculated to be 2.07 (table S1a) which unequivocally establishes the +2 oxidation state of the central Ni atom in complex $\mathbf{1}$. Similarly BVS values are: $\mathrm{Co}^{\mathrm{III}}-\mathrm{O}=1.79 \AA, \mathrm{Co}^{\mathrm{III}}-\mathrm{N}=1.68 \AA^{29,30}$ and calculated BVS value of Co is 3.35 (table S1b) which again establishes the +3 oxidation state for the central cobalt atom in complex 2 .

\section{Conclusion}

In conclusion, two mononuclear complexes of a hexacoordinating Schiff base ligand with $\mathrm{N}_{4} \mathrm{O}_{2}$ donor atoms have showed helical twist topology. Both complexes exhibit strong $\mathrm{H}$-bonding and $\mathrm{CH} \cdot \cdots \pi$ (phenyl) interactions that fall in the range $2.884-3.554 \AA$ for complex 1 and 3.265-3.441 $\AA$ for 2 to generate 1D chain. The bond valence sum (BVS) calculations clearly indicate that $\mathrm{Co}$ is in +3 oxidation state in complex 2 while $\mathrm{Ni}$ is in +2 oxidation state in $\mathbf{1}$.

\section{Supplementary Information}

The electronic Supplementary Information can be seen at www.ias.ac.in/chemsci.

\section{Acknowledgements}

Financial support from CSIR (Ref. 02(2490)/11/EMRII) New Delhi, is gratefully acknowledged. M D gratefully acknowledges UGC for the Fellowship (UGCNET). Special thanks to Atanu Jana and Saugata Konar [SRF (CSIR, NET)], Department of Chemistry, Calcutta University for their kind cooperation.

\section{References}

1. Sigel A, Sigel H and Sigel R K O (eds.) 2007 Metal ions in life science, Nickel and its impact in nature, (Chichester: John Wiley)

2. Cotton F A, Wilkinson G, Murillo C A and Bochmann M 1999 In Advanced Inorganic Chemistry, 6th Ed. (New York: Wiley Interscience) p 838

3. Ragsdale S W 2009 J. Biol. Chem. 28418571

4. Halcrow M A and Christou G, 1994 Chem. Rev. 942421

5. Gordon J C and Kubas G J 2010 Organometallics 294 682

6. Heinekey D M 2009 J. Organomet. Chem. 6942671

7. Bouwman E and Reedijk J 2005 Coord. Chem. Rev. 249 1555
8. Panda R, Zhang Y G, McLauchlan C C, Rao P V T, de Oliveira F A, Munck E and Holm R H 2004 J. Am. Chem. Soc. 1266448

9. Rao P V, Bhaduri S, Jiang J F, Hong D and Holm R H 2005 J. Am. Chem. Soc. 1271933

10. Lehn J-M 1995 In Supramolecular Chemistry (Weinheim: VCH)

11. Lindsey J S 1991 New J. Chem. 15153

12. Cramer F, Chaos and Order 1993 In The Complex Structure of Living Systems (Weinheim:VCH)

13. (a) Piguet C and Bünzli J -C G 1996 Eur. J. Solid State Inorg. Chem. 33 165; (b) Bünzli J-C G, Froidevaux P and Piguet C 1995 New J. Chem., 19661

14. (a) Sleiman H, Baxter P, Lehn J-M and Rissanen K 1995 J. Chem. Soc., Chem. Commun. 715; (b) Chambron J-C, Dietrich-Buchecker C O, Nierengarten J-F, Sauvage J P, Solladie' N, Albrecht-Gary A-M and Meyer M 1995 New J. Chem. 19 409; (c) Hanan G S, Arana C R, Lehn J-M and Fenske D 1995 Angew.Chem., Int. Ed. Engl. 34 1122; (d) Baxter P, Hanan G S and Lehn J-M 1996 Chem. Commun. 2019

15. Baxter P, Lehn J-M, Fischer J and Youinou M T 1994 Angew.Chem. Int. Ed. Engl. 332284

16. (a) Sauvage J-P 1990 Acc. Chem. Res. 23 319; (b) Dietrich-Buchecker C O and Sauvage J-P 1987 Chem. Rev. 87795

17. (a) Nabeshima $T$, Inada $T$, Furukawa $N$, Hosoya $T$ and Yano Y 1993 Inorg. Chem. 32 1407; (b) Nabeshima T 1996 Coord. Chem. Rev. 148151

18. Schneider H J 2009 Angew. Chem., Int. Ed. 483924

19. Braga D, Giaffreda S L, Grepioni F, Maini L and Polito M 2006 Coord. Chem. Rev. 2501267

20. Nishio M. 2004 Cryst. Eng. Comm. 6130

21. Tsuzuki S and Fujii A 2008 Phys. Chem. Chem. Phys. 102584

22. Tewari A K and Dubey R 2008 Bioorg. Med. Chem. 16 126

23. Sheldrick G M 2002 SAINT (Version 6.02), SADABS (Version 2.03), Bruker AXS Inc., Madison, Wisconsin

24. (a) Sheldrick G M 2007 Acta Crystallogr., Sect. A: Found. Crystallogr. 64 112; (b) Sheldrick G M 1997 SHELXL-97, Crystal Structure Refinement Programme, University of Göttingen

25. (a) Gupta S K, Hitchcock P B and Kushwah Y S 2002 Polyhedron 21 1787; (b) Ware D C, Denny WA and Clark G R 1997 Acta Crystallogr. Sect. C 53 1058; (c) Ware D C, Wilson W R, Denny W A and Rickard C E F 1991 J. Chem. Soc. Chem. Commun. 1171; (d) Weiss M C, Bursten B B, Peng S -M and Goedken V L 1976 J. Am. Chem. Soc. 988021

26. Meurer K P and Vögtle F 1985 Top. Curr. Chem. 1271

27. Vögtle F and Weber E 1979 Angew. Chem. Int. Ed. Engl. 18753

28. Pinkerton M and Steinrauf L K 1970 J. Mol. Biol. 49 533

29. (a) Palenik G J 1997 Inorg. Chem. 36 122; (b) O'Keeffe M and Brese N E 1991 J. Am. Chem. Soc. 113 3226

30. Brown I D and Altermatt D 1985 Acta Cryst. B 41244 